\title{
BMJ European Public Assessment Report Open (EPAR) summaries for the public: are they fit for purpose? A user-testing study
}

\author{
David K Raynor, ${ }^{1,2}$ David Bryant ${ }^{2}$
}

To cite: Raynor DK, Bryant D. European Public Assessment Report (EPAR) summaries for the public: are they fit for purpose? A user-testing study. BMJ Open 2013:3:e003185. doi:10.1136/bmjopen-2013003185

- Prepublication history for this paper is available online. To view these files please visit the journal online (http://dx.doi.org/10.1136/ bmjopen-2013-003185).

Received 8 May 2013 Revised 15 July 2013 Accepted 16 July 2013

${ }^{1}$ School of Healthcare, University of Leeds, Leeds, West Yorkshire, UK ${ }^{2}$ Luto Research, Leeds Innovations Centre, Leeds, West Yorkshire, UK

Correspondence to Professor David K Raynor; d.k.raynor@leeds.ac.uk

\section{ABSTRACT}

Objectives: Apply 'user testing' methodology to test the readability of a European Public Assessment Report (EPAR) summary-which describes how the decision was made by the European Medicines Agency to approve a medicine.

Design: User testing uses mixed methods (questionnaire and semistructured interview), applied iteratively, to assess document performance-can people find and understand key points of information.

Setting and participants: Testing was undertaken with 40 members of the public in four consecutive rounds of 10. Inclusion criteria, matched across rounds, included range of ages and educational attainment.

Tested documents: In round 1 we tested 19 key points of information in a printed version of the EPAR summary for Bondronat (a cancer medicine). This was then revised to address the findings, and tested in round 2 . In round 3 we tested the summary on-screen, and in round 4 , tested a revised on-screen version, after addressing findings from both rounds 1 and 3 .

Primary outcome measure: The target followed European guidance for medicine leaflets: for each point of information $90 \%$ of participants should be able to find, and of those, $90 \%$ able to show understanding of the point.

Results: For the original EPAR summary, 6 of the 19 points of information reached the target (both paperbased and on-screen). After revisions to format and content, using good practice in information writing and design, 14 and 16 points, respectively, met the target. The problems related to both finding (dependent on layout, headings and design) and understanding (words and sentences used, as well as design). We devised a new heading structure, increased use of bullet points, replaced difficult and technical words and divided long sentences.

Conclusions: People had difficulty finding and understanding key messages in the summary, but user testing identified the problems, and application of good practice resulted in a revised format which performed well.

\section{INTRODUCTION}

European Public Assessment Report (EPAR) summaries are designed to inform members

\section{ARTICLE SUMMARY}

Strengths and limitations of this study

- This is the first study using a performance-based method to assess the readability of these documents-determining whether people can find and understand the information they need.

- Only one document was tested, but it is typical of the nature of EPAR summaries, and most improvements identified were generic and could be applied across all such documents.

of the general public about how the European Medicines Agency (EMA) assess the risks and benefits of a new medicine, before deciding to grant a licence. ${ }^{1}$ They are developed with input from patient and consumer organisations, with each summary being reviewed for readability and publicfriendly language by a relevant patient prior to publication, but no testing of their readability is undertaken with members of the general public.

The summaries are based on the full European Public Assessment Report, prepared by the EMA for all medicines licensed by the Agency. This full report is said to "Reflect the scientific conclusion reached ... at the end of the centralised evaluation process." The full report is lengthy and written for professionals. Hence, the decision to produce a summary, lay version "written in manner understandable to the public." ${ }^{\prime}$ The EPAR summaries are available on the EMA website, but relatively little is known about the usefulness of these documents for members of the public, for whom they are designed.

To test their usefulness, the performancebased process for assessing the readability of documents called 'user testing' was employed. This method is routinely used for the mandatory leaflets for patients produced by manufacturers and included in every medicine pack. ${ }^{23}$ The use of the same testing approach 
for EPAR summaries is supported by the fact that they have significant similarities to patient leaflets. ${ }^{4}$ They are both relatively short documents, and based on long complex documents designed for professionals (the Summary of Product Characteristics or SmPC in the case of patient leaflets) - but revised to meet the needs of lay people. User testing determines whether potential readers can find and understand key points of information, as well as generating general feedback on the extent to which the information meets people's needs. ${ }^{5}$ The process has been successfully used and reported for a variety of health information for patients, including clinical trial patient information sheets, ${ }^{6}$ medicine label wordings ${ }^{7}$ and nationally produced medicines information booklets. ${ }^{5}$

This work was undertaken in the wider context of health literacy, which is not just the ability to read and understand health information, but is now acknowledged to have a wider scope. Essentially, it has three aspects- the ability to read and understand health information, the removal by healthcare systems of unnecessary complexity and barriers to patient understanding and involvement and a wider ability to engage with the healthcare process. ${ }^{8}$ In terms of EPAR summaries, the three aspects relate to whether people read and understand EPAR summaries, whether they contain barriers to patient understanding (both are the focus of this study) and do these documents enable people to better engage in decisions about medicines (for future study).

The objective was to test, then revise and retest, an EPAR summary (in both hard copy and on-screen formats) using user-testing methodology to assess whether the target audience, members of the public, can find and understand the key messages.

\section{METHODS}

We chose to test the EPAR summary for Bondronat, which contains ibandronic acid, a 'bis-phosphonate' medicine. It is used to treat cancers when there are high levels of calcium in the blood, and breast cancer in particular, when it has spread to the bone. The Bondronat summary was chosen because the data were based on more than one trial and its size is representative of most EPAR summaries-between one and two pages long.

User testing is a process which uses mixed methods to identify problems readers have with written information. Good practice is then applied, designed to address the problems identified. There are many texts on good practice in information writing and design, and two publications have pulled together such good practice for people writing medicines information. First, a UK review of medicines information for patients ${ }^{9}$ (commissioned by the Department of Health) included an information design review, informed by five experts in information design, which was subsequently published in the form of key principles to guide the development of consumer medicine information. ${ }^{10}$ Second, the European Union (EU) guideline on readability for package leaflets ${ }^{11}$ was written to ensure such information was accessible and understandable, and is widely used in the domain. These two complementary sources were used to guide the revisions of the EPAR summaries-each time followed by retesting to assess the effect of the revisions made. The process has both a quantitative component, using an administered questionnaire, and a qualitative component, using a semistructured interview, both of which generate feedback on how the information performs-used to revise the document, prior to retesting. ${ }^{3}$

\section{Participants}

The method used was in line with regulatory guidance on user testing for package leaflets, ${ }^{11}{ }^{12}$ that is, undertaken with people from the target group for the document-the general public. They were included if they could speak English to native standard. They were recruited from the database of Luto Research, the university spin out company which undertook the usertesting interviews. The database draws on people in the Leeds area of the North of England, and comprises people who have volunteered to take part in the testing of health information materials. People were excluded if they were current or retired healthcare professionals, took the medicine or had the indicated condition personally (or related conditions) or were carers of such people-as such people would have prior knowledge, and so it would not be a fair test of the information. In line with common practice in user testing, there were 10 participants in each round with

- At least three participants of each gender.

- Participants across the age range for the medicine. As the medicine is used more often by middle-aged and elderly people were recruited, at least one person in each of the 40s, 50s, 60s and 70-plus age groups, with no more than three people under the age of 40.

- No more than two higher education graduates.

- At least two participants who either do not use written documents as part of their work, or who are currently not working or are retired.

A new set of participants was used in each round, to prevent a learning effect. Participants were recruited in order that age, gender, education and use of literature (people who used written documents regularly at work vs those who did not, were not working or were retired) were equally matched across the four rounds of testing.

\section{Materials tested}

EPAR summaries are available on the EMA website in each of the official languages of the EU-we tested the English version. 
Round 1

The first document tested was the printed version of the Bondronat EPAR summary, downloaded directly from the EMA website on 23 August 2010 (see figure 1).

\section{Round 2}

A revised hard copy version was tested, revised according to the short-comings identified in the first round (see figure 2). Both documents were printed in black and white on two single-sided A4 sheets and stapled in the top left corner.

\section{Round 3}

The EPAR summary was shown to participants directly on a computer screen in its original format from the EMA website between 19 and 27 May 2011 (see figure 3).

\section{Round 4}

After revision, subsequent to the outcome of round 3, a revised version was tested, as a webpage mock up equivalent to the original website, opened in an equivalent Internet browser (see figure 4).

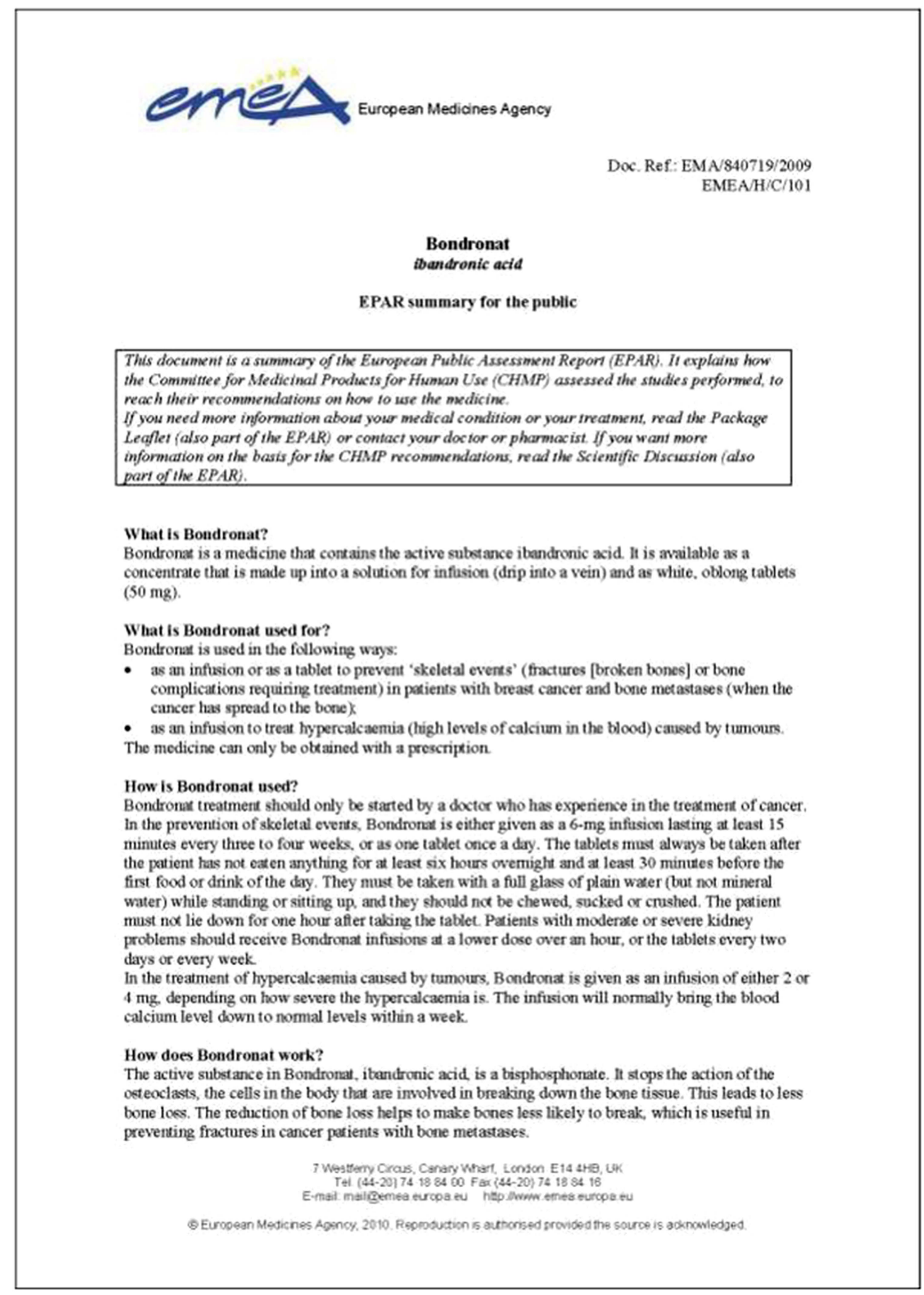

Figure 1 The original EPAR summary on paper (round 1). 
Patients with tumours can have high levels of calcium in their blood, released from the bones. By preventing the breakdown of bones, Bondronat also helps to reduce the amount of calcium releasod into the blood.

How has Bondronat been studied?

In the prevention of skeletal events in patients with breast eaneer and bone metastases, Bondronat has In the prevention of skeletal events in paticnts with breast cancer and bone metastases, Bondronat has
been compared with placebo (a dummy treatment) in three main studies lasting two years: one with the infusions in 466 patients and two with the tablets in a total of 846 patients. The main measure of effectiveness was based on the number of new bone complications. These included spine fractures. fractures outside the spine and any bone complications that needed treatment with radiotherapy or surgery.

Bondronat has also been studied in the treatment of hyperealcacmia caused by tumours in three fourweck studio involving a total of 343 paticnts. Bondronat was not compared with any other treatments in these studies. The main measure of effectiveness was the change in blood calcium levels.

What benefit has Bondronat shown during the studies?

Bondronat was more effective than placebo in preventing bone complications, It took longer for paticnts on Bondronat infusions or tablets to develop a new bone complication ( 50 to 76 wecks) than for patients on placebo ( 33 to 48 wecks). Bondronat reduced the risk of having a skeletal event by about $40 \%$ compared with placebo.

Bondronat was also effoctivo in treating hypercalcacmia caused by tumours. About a half to two-thirds of the patients responded to a 2-mg dose of Bondronat, with blood calcium levels retuming to within the nomal range, About three-quarters rexponded to a 4 -mg dose.

What is the risk associated with Bondronat?

The most common side effoct with Bondronat infusions (secn in more than 1 pationt in 10) is pyrexia (fover). The most common side effects with the tablets (seen in between 1 and 10 patients in 100) are hypocalcacmia (low blood calcium lovels), dyspepsia (heartbum), nausea (foeling sick), abdominal pain (stomach ache), oesophagitis (inflammation of the oosophagus, the tube that leads from the mouth to the stomach) and asthenia (weakness). For the full list of all side effocts reported with Bondronat, see the Package L.eaflet.

Bondronat should not be used in people who may be hypersensitive (allergic) to ibandronic acid or any of the other ingredients. It must not be used in people with hypocalcacmia, and should be used with caution in patients who are sensitive to other bisphosphonates. The tablets must not be used in patients who have abnormalities of the oesophagus or who cannot stand or sit upright for at least an hour. Bondronat should not be usod in children.

Why has Bondronat been approved?

The Committo for Medicinal Products for Human Use (CHMP) docided that Bondronat's benefits are greater than its risks and recommended that it be given marketing authorisation.

Other information about Bondronat:

The European Commission granted a marketing authorisation valid throughout the European Union for Bondronat on 25 June 1996. The marketing authorisation holder is to Roche Registration Limited. The marketing authorisation is valid for an unlimited period.

The full EPAR for Bondronat is available here

This summary was last updated in 01-2010.

Figure 1. Continued.

\section{Procedure}

The document was examined by two pharmacists in the team (DKR, DB) to identify the most important points of information in the document. There were 19 points considered to be the most critical information (see figure 5), under the categories:

- Purpose of the report and its origins (2 points);

- Nature of the medicine and its use (3 points);

- Studies that have been undertaken (5 points);

- Specific issues regarding the risks of Bondronat (4 points);

- Decision to grant a licence (3 points);

- Finding more information (2 points).

A questionnaire was then designed to assess whether people could find and understand each key point of information. The questions were set in the questionnaire in an order that did not follow the sequence in the document.

The objective of the user test in line with current European guidance for patient leaflets, ${ }^{11}$ is for $90 \%$ of participants to find the information in the document, and of those, $90 \%$ to be able to show that they have understood it.

Participants were interviewed individually by one of the three experienced trained interviewers in purposebuilt interview rooms, and guidance for interviewers in the questionnaire ensured consistent conduct of the interviews. Consistent scoring of the responses was guided by 'indicative answers' for each question; that is, the information from the leaflet that the participant was required to provide for the answer to be scored as understood. For example, for the question "What two 


\section{Summary European Public Assessment Report for Bondronat (also called "ibandronic acid")}

\section{About this Summary European} Public Assessment Report

Who this report is for

This "Summary European Public Assessment Report" contains information for the general public.

- The purpose of the report is to explain how it was decided to make Bondronat available to patients in Europe.

What this report contains

This report describes the research which has been done on the medicine. It describes what this research tells us about:

- the benefits of the medicine and

- the risks of the medicine.

It then explains how the benefits and risks were weighed-up before a decision was made to approve it.

Who made the decision

The decision was made by a group called the

- "Committee for Medicinal Products for Human Use" or CHMP for short.

This is a group of experts including doctors and pharmacists. They work for the govemment and in universities. They are not connected to the company that developed the medicine.

Where to get more information This report is a shorter simpler version of the main report - called the "European Public Assessment Report" (EPAR)

- If you want more information about how the decision was made, you can find the full report on www.ema.europa.eu. You should look particularly at the section called "Scientific Discussion".

- If you want more general information about Bondronat, read the package leaflet that comes with the medicine and on www.medicines.org. You can also talk to a doctor or pharmacist.

\section{In this leaflet}

1. What Bondronat is and what it is used for

2. How Bondronat is used

3. How Bondronat was studied

4. Possible side effects of Bondronat

5. Why Bondronat was approved

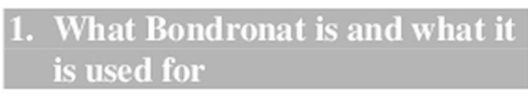

What type of medicine is Bondronat?

Bondronat contains a medicine called

"ibandronic acid". This belongs to a group of medicines called "bis-phosphonates". You need a doctor's prescription to get Bondronat.

How is Bondronat given?

Bondronat is given as:

- a drip (an 'infusion') - into a vein

- a tablet - swallowed

What Bondronat is used for

Bondronat is used:

In cancers where there are high levels of calcium in the blood.

- The high levels are caused by the tumour.

- This high level is called "hypercalcaemia".

- Here Bondronat is given as a drip.

In breast cancer to prevent fractures (broken bones) or bone complications.

- This is when the cancer has spread to the bone (called "metastases")

- Here Bondronat is given as a drip or a tablet.

How Bondronat works

In the body there are cells called "osteoclasts" These cells help break down the bone tissue.

In cancers where there are high levels of calcium in the blood.

- This calcium comes from the bones.

- This high level of calcium can cause side effects.

- By preventing the breakdown of bones, Bondronat helps to reduce the amount of calcium released into the blood.

In breast cancer patients.

- These patients are at risk of fractures, when the cancer has spread to their bones.

- Because Bondronat causes less bone loss, these fractures are less likely.

Please turn over for more information

Figure 2 The revised EPAR summary on paper (round 2).

things were weighed up before the decision was made about whether Bondronat should be approved," the indicative answer was "(Bondronat's/its) benefits AND risks."

The responses to the short semistructured interviews were audio-recorded and transcribed verbatim. We looked for recurring patterns of comments and selected key quotes which illustrated these points.

The questionnaire and original EPAR summary were pilot tested with three people from a convenience sample to determine whether the questions worked in practice.

\section{Round 1 (original; paper)}

The questionnaire was administered to 10 people from the target group, interviewed individually, with each participant first given time to read the EPAR summary at their own pace. Then, using the EPAR summary supplied, they were asked to find the information relevant 
. How Bondronat is used

Bondronat should only be started by a doctor who has experience in treating cancer.

For high calcium levels

Bondronat is given as a drip

- This is either a 2 or 4 milli-gram $(\mathrm{mg})$ drip.

- The amount depends on how high the calcium levels are.

The drip will normally bring the blood calcium level down to normal levels within a week.

\section{To prevent fractures}

To prevent fractures, Bondronat is given as:

- 6 milli-gram (mg) drip over at least 15 minutes - every three to four weeks or

- one tablet once a day in the early morning.

Special information about taking the tablets

1. The tablets have to be taken when the stomach is empty. This is because food may stop the medicine from getting into the body from the stomach. This means the best time is first thing in the morning.

- Before taking the tablet, the patient must not eat anything for at least six hours overnight

- After taking the tablet, the patient must wait at least 30 minutes before the first food or drink of the day.

2. The tablets can irritate your food pipe. The food pipe is the tube from the mouth to the stomach. This means the tablets must be taken:

- whole - not chewed, sucked or crushed

- with a full glass of plain water (not sparkling water)

- while standing or sitting up

The patient must not lie down for one hour after taking the tablet.

\section{Patients with kidney problems}

Patients with moderate or severe kidney problems should have Bondronat infusions at a lower dose over an hour. If taking the tablets, they take them every two days or every week.

Please see the next column for more information

\section{How Bondronat was} studied

Research studies into bone complications

There have been 3 main research studies of

Bondronat in preventing fractures in patients

with breast cancer where the cancer has spread

to the bone:

- one study with the drip - in 466 patients

- two studies with the tablets -in a total of 846 patients.

What was Bondronat compared with?

In these studies, Bondronat was compared with "dummy" treatment. This is where the drip or tablets contain no medicine (also called a 'placebo'). These studies each lasted 2 years. What did the studies look for?

The studies looked for the number of new bone problems or complications. These included spine and other fractures. Also any bone problems that needed radiotherapy or surgery.

What did the studies show?

The results showed Bondronat was more effective than dummy treatment in preventing bone problems.

- Patients having Bondronat infusions or tablets did not get new bone problems until 50-76 weeks. This compared with 3348 weeks for patients on the dummy treatment.

- Bondronat reduced the risk of having a fracture or other bone problem by about $40 \%$ compared with placebo.

Research studies into high calcium levels

There have been 3 main studies in the treatment of high calcium levels caused by tumours. These lasted four weeks and involved 343 patients.

What was Bondronat compared with?

Bondronat was not compared with any other treatments in these studies.

What did the studies look for?

The studies looked at any changes in blood calcium levels.

What did the studies show?

The results showed that Bondronat was effective in reducing high calcium levels caused by tumours:

- A 2 milli-gram $(\mathrm{mg})$ dose made the levels return to normal in about half to two-thirds of patients

- A 4 milli-gram (mg) dose worked in about three-quarters of patients.

Figure 2. Continued.

to each of the 19 questions and then to explain it in their own words (see table 1).

For each question, the interviewer noted any comments or particular behaviour of the participants. At the end of the interview, participants were asked for feedback about the EPAR summary.

\section{Round 2 (revised; paper)}

The original EPAR summary was then refined by an experienced health information writer (DKR), focusing on the difficulties identified during the testing, and participants' general comments about the usefulness of the document. These revisions were made using best practice in information writing and design (see above). This revised EPAR summary was tested on 10 more people from the target group for this product.

Rounds 3 and 4 (original; electronic and revised; electronic) As EPAR summary documents are available in an electronic format, two further rounds of testing were conducted 


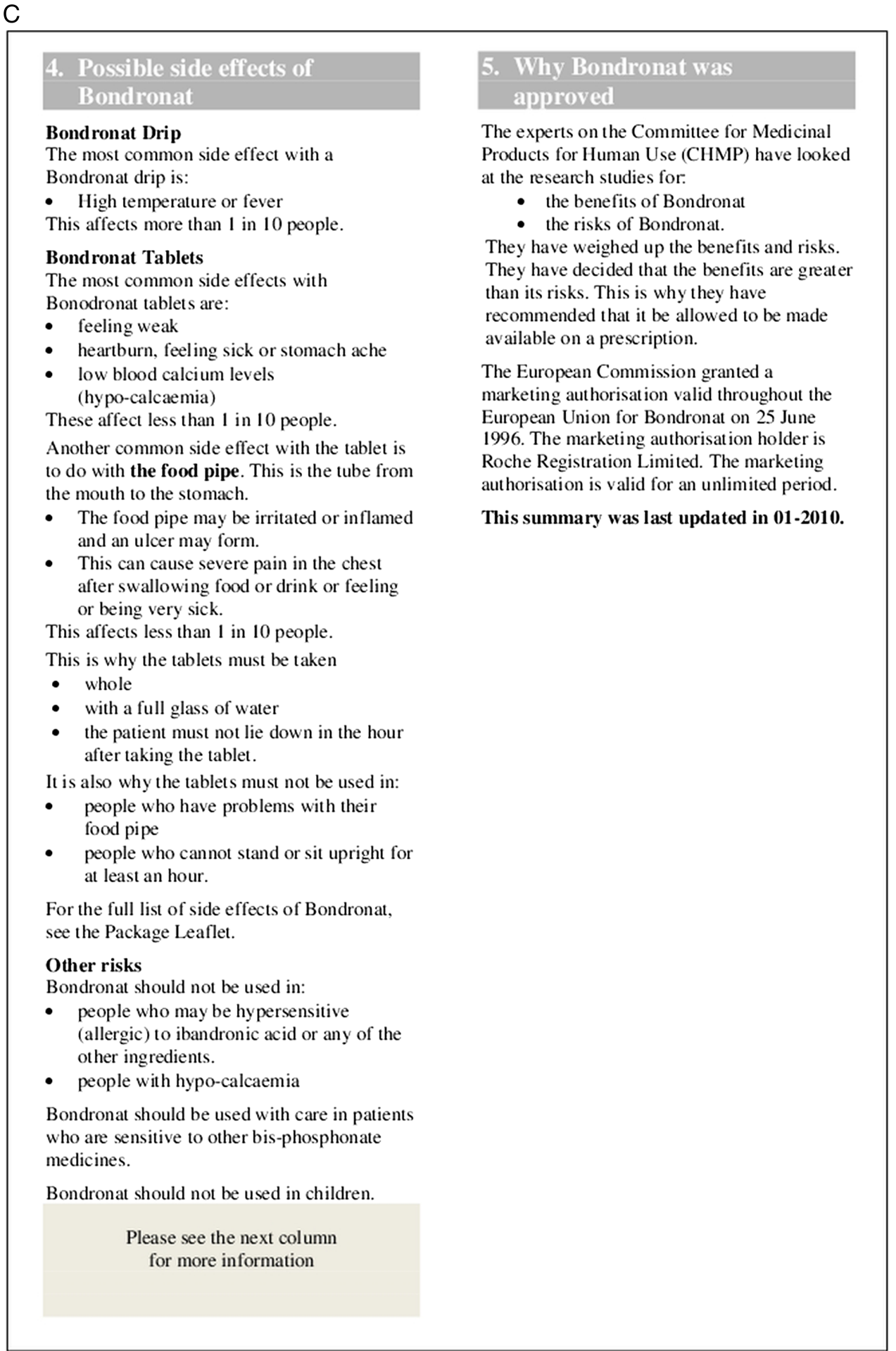

Figure 2 Continued.

on-screen, to test both the original and then a revised EPAR summary. For each version, 10 people from the target group were interviewed, this time referring to the information on a computer screen rather than in printed form. Inclusion criteria for these rounds additionally included:

- Five people who use computers often (at least once a day).

- Five people who use computers occasionally (not every day).
We anticipated applying the learnings from the hard copy testing to the subsequent on-screen testing.

\section{RESULTS}

Forty eligible participants were interviewed in four rounds of 10; their characteristics in terms of gender, age range, educational status and use of literature at 
Table 1 European Public Assessment Report summary paper version: original (round 1) and revised (round 2)

\begin{tabular}{|c|c|c|c|c|}
\hline \multirow[b]{2}{*}{ Questions } & \multicolumn{2}{|l|}{ Original (round 1) } & \multicolumn{2}{|l|}{ Revised (round 2) } \\
\hline & $\begin{array}{l}\text { Number of points } \\
\text { found/understood }\end{array}$ & $\begin{array}{l}\text { Target } \\
\text { met? }\end{array}$ & $\begin{array}{l}\text { Number of points } \\
\text { found/understood }\end{array}$ & $\begin{array}{l}\text { Target } \\
\text { met? }\end{array}$ \\
\hline 1 Who has this report been written for? & $7 / 7$ & No & $8 / 8$ & No \\
\hline 2 When is Bondronat used in breast cancer? & $9 / 4$ & No & $10 / 7$ & No \\
\hline 3 What is the purpose of this report? & $7 / 0$ & No & $9 / 9$ & Yes \\
\hline 4 What can the tablets do to the food pipe? & $10 / 0$ & No & $10 / 10$ & Yes \\
\hline $\begin{array}{l}5 \text { Who made the decision about Bondronat described in } \\
\text { this report? }\end{array}$ & $10 / 1$ & No & $9 / 9$ & Yes \\
\hline 6 What group of medicines does Bondronat belong to? & $7 / 7$ & No & $10 / 10$ & Yes \\
\hline $\begin{array}{l}7 \text { What did Committee for Medicinal Products for Human } \\
\text { Use (CHMP) decide about Bondronat? }\end{array}$ & $10 / 10$ & Yes & $10 / 10$ & Yes \\
\hline $\begin{array}{l}8 \text { The tablets can irritate the food pipe. Which people } \\
\text { cannot have the tablets as a result of this? }\end{array}$ & $9 / 8$ & Yes & $10 / 8$ & No \\
\hline $\begin{array}{l}9 \text { What two things were weighed up before decision made } \\
\text { about whether Bondronat should be approved? }\end{array}$ & $7 / 7$ & No & $10 / 10$ & Yes \\
\hline $\begin{array}{l}10 \text { How does Bondronat prevent fractures, or broken } \\
\text { bones? }\end{array}$ & $10 / 9$ & Yes & $8 / 7$ & No \\
\hline $\begin{array}{l}11 \text { In the studies looking into bone problems or } \\
\text { complications, what was looked at to see if Bondronat } \\
\text { was working? }\end{array}$ & $5 / 4$ & No & $10 / 9$ & Yes \\
\hline $\begin{array}{l}12 \text { During the studies into high calcium levels, how many } \\
\text { people did the } 4 \mathrm{mg} \text { dose work in? }\end{array}$ & $9 / 9$ & Yes & $10 / 10$ & Yes \\
\hline $\begin{array}{l}13 \text { How many people receiving a Bondronat infusion got a } \\
\text { fever? }\end{array}$ & $10 / 3$ & No & $10 / 8$ & No \\
\hline $\begin{array}{l}14 \text { During the study of bone complications, what was } \\
\text { Bondronat compared with? }\end{array}$ & $9 / 9$ & Yes & $10 / 10$ & Yes \\
\hline $\begin{array}{l}15 \text { Suppose you want more information on how the } \\
\text { decision was made about Bondronat, what should you } \\
\text { do? }\end{array}$ & $9 / 1$ & No & $10 / 9$ & Yes \\
\hline $\begin{array}{l}16 \text { How many people taking the Bondronat tablet got an } \\
\text { inflamed food pipe? }\end{array}$ & $10 / 5$ & No & $10 / 9$ & Yes \\
\hline $\begin{array}{l}17 \text { In the research studies of high calcium levels in the } \\
\text { blood, what was Bondronat compared against? }\end{array}$ & $9 / 9$ & Yes & $9 / 9$ & Yes \\
\hline $\begin{array}{l}18 \text { When Bondronat was studied in the treatment of bone } \\
\text { complications, which group of patients got a new bone } \\
\text { problem first? }\end{array}$ & $8 / 8$ & No & $9 / 9$ & Yes \\
\hline $\begin{array}{l}19 \text { If you are a patient and want more information about } \\
\text { Bondronat, what should you do? }\end{array}$ & $8 / 7$ & No & $10 / 10$ & Yes \\
\hline Total number of passes & & 6 & & 14 \\
\hline
\end{tabular}

work were matched across all four rounds and are described in table 2.

Round 1: original paper version

Quantitative findings

In the first round of testing, with the original document in paper format, 6 of the 19 items of information met the target of $90 \%$ finding and $90 \%$ of those understanding (see table 1).

Qualitative findings

Participants' comments on the layout of the information were mixed; some criticised it

Table 2 Demographics of participants in each round

\begin{tabular}{lllll}
\hline & Female (F) or male (M) & Age range & Educational status ${ }^{*}$ & Use of literature at work $\dagger$ \\
\hline Round 1 (10) & $7 \mathrm{~F}, 3 \mathrm{M}$ & $29-74$ & $1=4,2=4,3=2$ & $\mathrm{Y}=3, \mathrm{~N}=7$ \\
Round 2 (10) & $7 \mathrm{~F}, 3 \mathrm{M}$ & $22-71$ & $1=4,2=4,3=2$ & $\mathrm{Y}=3, \mathrm{~N}=7$ \\
Round 3 (10) & $7 \mathrm{~F}, 3 \mathrm{M}$ & $26-72$ & $1=4,2=4,3=2$ & $\mathrm{Y}=3, \mathrm{n}=7$ \\
Round 4 (10) & $7 \mathrm{~F}, 3 \mathrm{M}$ & $21-73$ & $1=4,2=4,3=2$ & $\mathrm{Y}=3, \mathrm{~N}=7$ \\
\hline
\end{tabular}

*Educational status: $1=$ education complete by 16 years; $2=$ A-level or equivalent; $3=$ higher educational graduate.

†Use of literature at work: $\mathrm{Y}=\mathrm{yes}$ : uses written documents regularly at work; $\mathrm{N}=$ no: written document not used regularly at work, not working or retired. 
It's not user friendly for a start. It's more like something from a lecture $(\mathrm{P} 1)$

I found it quite difficult to find things ...they weren't where I'd expect them to be under the headings (P8)

One participant gave a more specific comment about the box at the top of the page

The little box at the top with italics...people miss out things like that, they'll think 'Oh it's the boring bit' (P3)

Others were more content with the layout:

Well set out (P 10)

Well laid out with the titles (P3)

Most participants said they did not have a problem with the language used in the leaflet. Participants described the language as fine, okay and straight forward among other things. However, one participant (P1) said it was too technical and another said

There's all these big words and big sentences (P5)

\section{Revising the EPAR summary}

The revision took account of the results from the first round of testing-both quantitative and qualitative, where it was shown that improvements were needed.
The revision also took account of good practice in information writing and design (see above). ${ }^{10}$

There were eight questions where, of the 10 participants, 5 or less could find and understand the information. Specific changes were made to address the issues with these points of information and are described in table 3 .

As well as the changes in response to specific difficulties with answering the questions, other general changes made in line with good practice in information writing and design ${ }^{1011}$ were

- Information split over two columns-some readers struggle with long lines of text.

- Boxes surrounding text removed-some readers 'read round' boxed information.

- Text and headings justified to the left ('ragged right') - text justified to left and right leads to unequal gaps between words which can hinder ease of reading.

- Bold text used as it is effective in giving emphasisreplacing underlined, italicised or capitalised text (which can make reading harder).

- Some paragraphs organised into bullet points-helps to organise text for readers, and aids finding as well as making document look more approachable.

- Technical or medical terms replaced with lay language-for example, 'hypercalcaemia' became 'high calcium levels'.

Table 3 Changes made in round 1 related to the responses to specific questions

\begin{tabular}{l} 
Question \\
\hline 2 When is Bondronat used in breast cancer? \\
3 What is the purpose of this report? \\
4 What can the tablets do to the oesophagus or food \\
pipe?
\end{tabular}

5 Who made the decision about Bondronat described in this report?

11 In the studies looking into bone problems or complications, what was looked at to see if Bondronat was working?

13 How many people receiving a Bondronat infusion got a fever?

15 Suppose you want more information on how the decision was made about Bondronat, what should you do?

16 How many people taking the Bondronat tablet got an inflamed food pipe?

\section{Changes made}

Original long sentence with multiple bracketing incorporated into 2 new subheadings, separated into dedicated bullet points

Original text in italics in box at beginning became part of main document under new heading 'Who is this report for'

In original, mentioned both in the 'How is Bondronat used' section and 'What is the risk' section in isolation. Changed so clear in both places what problem was, and how it related to necessary actions

Original did not make clear the membership of CHMPremedied in revised version under the heading 'Who made the decision?' in first section of the document

Answer was number of new bone complications-in original in middle of paragraph containing variety of pieces of information about the study. Revision included new subheading 'What did the studies look for'

Original listed side effects in long paragraph with long sentences. Revision bulleted the side effects, and separated out those relating to 'drip' and tablets

Information moved from original boxed italicised text into a new subsection titled 'Where to get more information'

Information became part of bulleted list of side effects (see above), and frequency simplified from 'seen in between 1 and 10 patients in a hundred' to 'affects less than 1 in 10 people' 


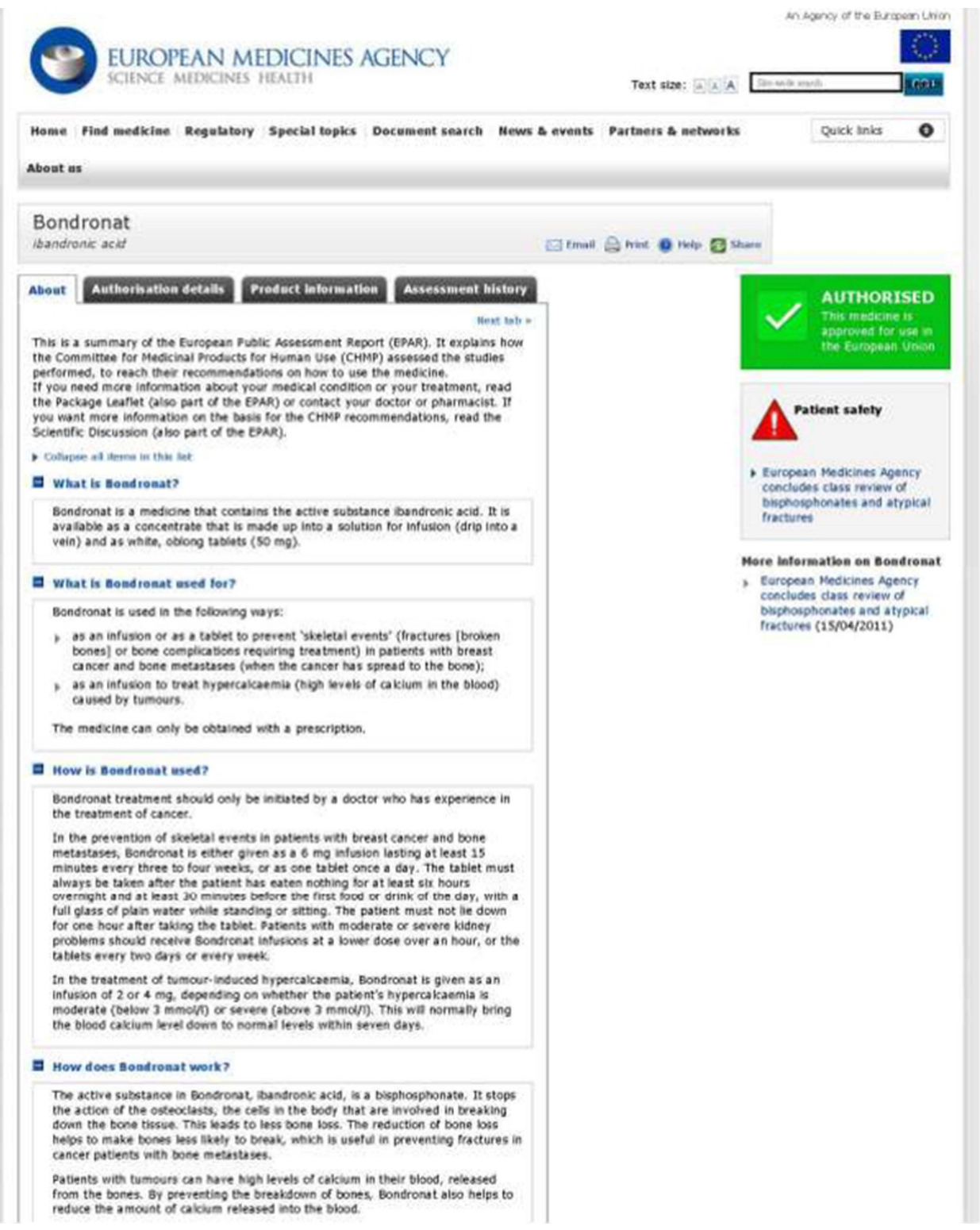

Figure 3 The original EPAR summary on screen (round 3).

Importantly, the structure was revised with a focus on making the document easier to navigate. It was split into six main headings, section numbers were introduced (see figure 6) and an index ('In this leaflet') was added to aid navigation. The main headings for each of the six sections of the leaflet were written as white text on a grey band which went across the column. This clearly demarcates the sections, helping readers to find the section they are looking for. Equally, the insertion of subheadings aids navigation, such as 'Who is this report for' and 'What type of medicine is Bondronat'.

Finally, instead of separating the information from the two types of studies (into how studied and what has been shown), the studies of bone complications and high calcium levels were given their own subheadings, and became self-contained.
As a result, revisions were made to the original EPAR summary to produce the revised version tested in round 2 (see figure 4).

\section{Round 2: revised paper version}

Quantitative findings

The objective remained that $90 \%$ of participants should be able to find the information in the leaflet and of those $90 \%$ should be able to understand it. As can be seen from table 1,14 of the 19 points of information now met this target.

\section{Qualitative findings}

Participants were generally positive about the layout of the revised EPAR summary. Comments included it was fine how it's laid out (P17) and it's logical (P20). Several 
a How has Bondronat been stadied?

In the prevention of skefetal events in patients with breast cancer and boos metastases, Bondroesat has been compared with placebo (a dummy treatment) chree main studies lasting trao yedrs: cee with the infusions in 466 partiots and was based on the number $d$ new tore complikations. Trese included saine fractures, fractures outsde the soine and any bone complicotions that reeded treatment with radicthera or of surgery.

Sondronat has aleo been studed in the treatment $\alpha$ hypercalcaemis cassed br tumours in three four-week studes invoring a tocat of 343 patikets. Condroedt of effectireness was the change in biood cakium levels.

a what benefit has Bondronat shown during the stadies?

Bondronat was more effective than placebo in prerentrop bone complications. It took bonger for patients on Bendronat infusicns or tabiets to derebop a sen boce

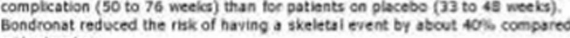
weth placebo

Bondronat was also effective in treating hypercakaemis caused by tumburs. About a half to two-thirds of the patients responded to a $2 . \mathrm{mg}$ doce of Bondronat, with bisod caloum leveis returning to vethin the normal range. Above throe -quarters responded to a 4-mg dose.

at what is the ribk associated with Boadreaat?

The most common side effect with Eondronat infunicons (seen in more than 1 patient in 10) is pyroxis (Gever). The most common sice effocts with the tubiets

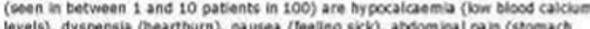

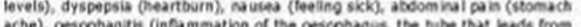

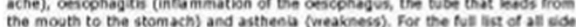
elfects reported with Bondronat, see tha package Lastet.

Bondronat should not be vied in pecole who may be hyperienstere (allergk) to bandronic acid of any of the other ingredients. It must not be wesed in peophe wie

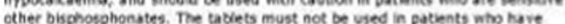

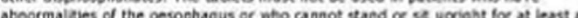
hout. Blondronat ahould not be wsed in chideren.

athy has Boedronat been approved?

The Committee for Medicinal products for Human Use (CHMP) decided that Bondronar's benetess are grester than its raks and recommendod that a be given marketing autherisation.

a other intormation about Bondroant

The Eurcpean Commission granted a marketing authorisation ra id throughoot the turcoest Unioe for Bondronat on 25 june 1996. The marketing suthcrisgtice hoider is to Roche Registration Umited. The marketing authoriation is valid for an unilimited period.

\begin{tabular}{|c|c|c|c|}
\hline Mane & Language & Fint publiabed & Lant updated \\
\hline $\begin{array}{l}\text { T) Bandronat: EPAR - } \\
\text { Summary for the } \\
\text { pobbic }\end{array}$ & $\begin{array}{l}\text { motron } \\
\operatorname{cor}\end{array}$ & $2006 \cdot 06-09$ & $2010 \cdot 03.08$ \\
\hline
\end{tabular}

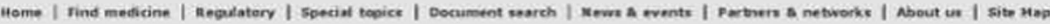

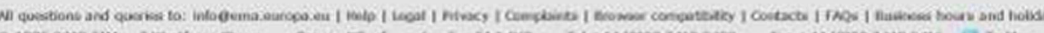

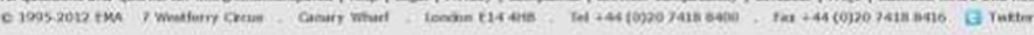

Figure 3 Continued.

participants made specific reference to the headings and the 'In this leaflet' index as positive features of the document, examples of comments were

I like how the headings are set out, which are set into sections which are easier to find (P18)

It's good the way you've got it laid out. 'In this leaflet' and it tells you which section's which (P13)

It is in bullet points and its easier to read than paragraph after paragraph of information (P14).

The language was well received and described as straight forward (P12) and very easy to understand (P18). Participants commented on the use of lay language, for example, participant 15 described the language used as everyday language.
Round 3: original electronic version

Quantitative findings

The objective that $90 \%$ of participants should be able to find the information in the leaflet and of those $90 \%$ should be able to understand it was met for 6 of the 19 points (see table 4).

\section{Qualitative findings}

As in round 1, comments on the original EPAR summary were mixed with regard to the layout; however, the layout of the electronic version seemed to be better received than the paper version. Positive comments included it looked straight forward $(\mathrm{P} 23)$ and It was easy to scroll down to whichever section your question applied to (P29). Participant 28 was more critical and suggested more care and attention to what you present under these various headings. 
Table 4 European Public Assessment Report summary screen versions: original (round 3) and revised (round 4)

\begin{tabular}{|c|c|c|c|c|}
\hline \multirow[b]{2}{*}{ Questions } & \multicolumn{2}{|l|}{ Original (round 3) } & \multicolumn{2}{|c|}{ Revised (round 4) } \\
\hline & $\begin{array}{l}\text { Number of points } \\
\text { found /understood }\end{array}$ & $\begin{array}{l}\text { Target } \\
\text { met? }\end{array}$ & $\begin{array}{l}\text { Number found/ } \\
\text { understood }\end{array}$ & $\begin{array}{l}\text { Target } \\
\text { met? }\end{array}$ \\
\hline 1 Who has this report been written for? & $4 / 0$ & No & $10 / 9$ & Yes \\
\hline 2 When is Bondronat used in breast cancer? & $9 / 1$ & No & $10 / 9$ & Yes \\
\hline 3 What is the purpose of this report? & $6 / 0$ & No & $9 / 9$ & Yes \\
\hline 4 What can the tablets do to the food pipe? & $10 / 0$ & No & $10 / 10$ & Yes \\
\hline $\begin{array}{l}5 \text { Who made the decision about Bondronat described in this } \\
\text { report? }\end{array}$ & $9 / 0$ & No & $10 / 9$ & Yes \\
\hline 6 What group of medicines does Bondronat belong to? & $5 / 5$ & No & $10 / 10$ & Yes \\
\hline $\begin{array}{l}7 \text { What did the Committee for Medicinal Products for } \\
\text { Human Use (CHMP) decide about Bondronat? }\end{array}$ & $9 / 8$ & Yes & $10 / 9$ & Yes \\
\hline $\begin{array}{l}8 \text { The tablets can irritate the food pipe. Which people } \\
\text { cannot have the tablets as a result of this? }\end{array}$ & $10 / 9$ & Yes & $9 / 8$ & Yes \\
\hline $\begin{array}{l}9 \text { What two things were weighed up before the decision was } \\
\text { made about whether Bondronat should be approved? }\end{array}$ & $3 / 3$ & No & $10 / 10$ & Yes \\
\hline 10 How does Bondronat prevent fractures, or broken bones? & $10 / 9$ & Yes & $7 / 6$ & No \\
\hline $\begin{array}{l}11 \text { In the studies looking into bone problems or } \\
\text { complications, what was looked at to see if Bondronat } \\
\text { was working? }\end{array}$ & $8 / 8$ & No & $7 / 7$ & No \\
\hline $\begin{array}{l}12 \text { During the studies into high calcium levels, how many } \\
\text { people did the } 4 \mathrm{mg} \text { dose work in? }\end{array}$ & $7 / 7$ & No & $10 / 9$ & Yes \\
\hline $\begin{array}{l}13 \text { How many people receiving a Bondronat infusion got a } \\
\text { fever? }\end{array}$ & $10 / 9$ & Yes & $10 / 9$ & Yes \\
\hline $\begin{array}{l}14 \text { During the study of bone complications, what was } \\
\text { Bondronat compared with? }\end{array}$ & $10 / 8$ & No & $10 / 10$ & Yes \\
\hline $\begin{array}{l}15 \text { Suppose you want more information on how the decision } \\
\text { was made about Bondronat, what should you do? }\end{array}$ & $7 / 2$ & No & $10 / 9$ & Yes \\
\hline $\begin{array}{l}16 \text { How many people taking the Bondronat tablet got an } \\
\text { inflamed food pipe? }\end{array}$ & $9 / 8$ & Yes & $10 / 10$ & Yes \\
\hline $\begin{array}{l}17 \text { In the research studies of high calcium levels in the blood, } \\
\text { what was Bondronat compared against? }\end{array}$ & $7 / 7$ & No & $9 / 9$ & Yes \\
\hline $\begin{array}{l}18 \text { When Bondronat was studied in the treatment of bone } \\
\text { complications, which group of patients got a new bone } \\
\text { problem first? }\end{array}$ & $6 / 5$ & No & $8 / 5$ & No \\
\hline $\begin{array}{l}19 \text { If you are a patient and want more information about } \\
\text { Bondronat, what should you do? }\end{array}$ & $9 / 9$ & Yes & $10 / 10$ & Yes \\
\hline Total number of passes & & 6 & & 16 \\
\hline
\end{tabular}

About half of the participants thought that the language was fine or okay. However, other participants were more negative. Comments included, unnecessarily formal and technical (P28) and it used a lot of big words (P23). One participant anticipated the team's revisions after round 1 by saying Why don't they put the easier words down instead of the big words and then in brackets put the smaller words (P22).

Two participants also made reference to the Package Leaflet, participant 28 noted that Package Leaflet, although mentioned, is not immediately available on the website. Participant 30 also commented to say that I'm realising this is an extra leaflet, it would be nice to see the proper leaflet because that's probably got it a lot clearer, how to take it.

\section{Revising the EPAR summary}

The changes made after the first round for the hard copy version were largely replicated in the revised on-screen version, as most of the problems identified were similar. However, a single column format was retained as this worked well in an on-screen format.

There were nine questions where of the 10 participants, 5 or less could find and understand the information. Of these, five questions (2-5 and 15) were addressed, as a result of problems with the hard copy original. This left four additional points to address, which are described in table 5 .

\section{Round 4: revised electronic version}

\section{Quantitative findings}

The objective that $90 \%$ of participants should be able to find the information in the leaflet and of those $90 \%$ should be able to understand it was met for 16 of the 19 points of information (see table 4).

\section{Qualitative findings}

The layout was generally well received by participants in this round. It was described as nice and clear (P31) and 
Table 5 Changes made in round 3 related to the responses to specific questions

\section{Questions}

1 Who has this report been written for?

6 What group of medicines does Bondronat belong to?

9 What two things were weighed up before the decision was made about whether Bondronat should be approved?

18 When Bondronat was studied in the treatment of bone complications, which group of patients got a new bone problem first?

\section{Changes made}

Dedicated subheading 'Who is this report for" introduced

This information, formerly in the section 'How does Bondronat work' repositioned in the new subsection 'What type of medicine is Bondronat'?

Information bulleted in revised version, to aid finding and understanding

Simplified through new subheading of 'What did the studies show? simple (P32). Participant 40 also mentioned the different sections of the leaflet and said that it was well structured and in different categories which all make sense.

In general, comments received about the language were positive. It was described as easy to understand (P31), and not complicated (P39).

There were varying views on the electronic presentation. Participant 32 said I love being able to do it on the screen. Whereas another participant thought that there is a lot of scrolling through the screen $(\mathrm{P} 40)$. Other comments included

It wouldn't be very much use to me reading it on a computer because I haven't got a computer (P34)

\section{Qualitative feedback on EPAR summaries in general}

Participants from all four rounds of testing were asked to provide feedback in terms of their opinions on EPAR summaries in general.

The majority $(32 / 40)$ of the participants interviewed thought that the information in the EPAR summary report would be useful.

If they could fight their way through it, it would be quite useful (P3)

It was good how they gave the background ... explain the benefits ... so people can see a reason for taking the drug (P33)

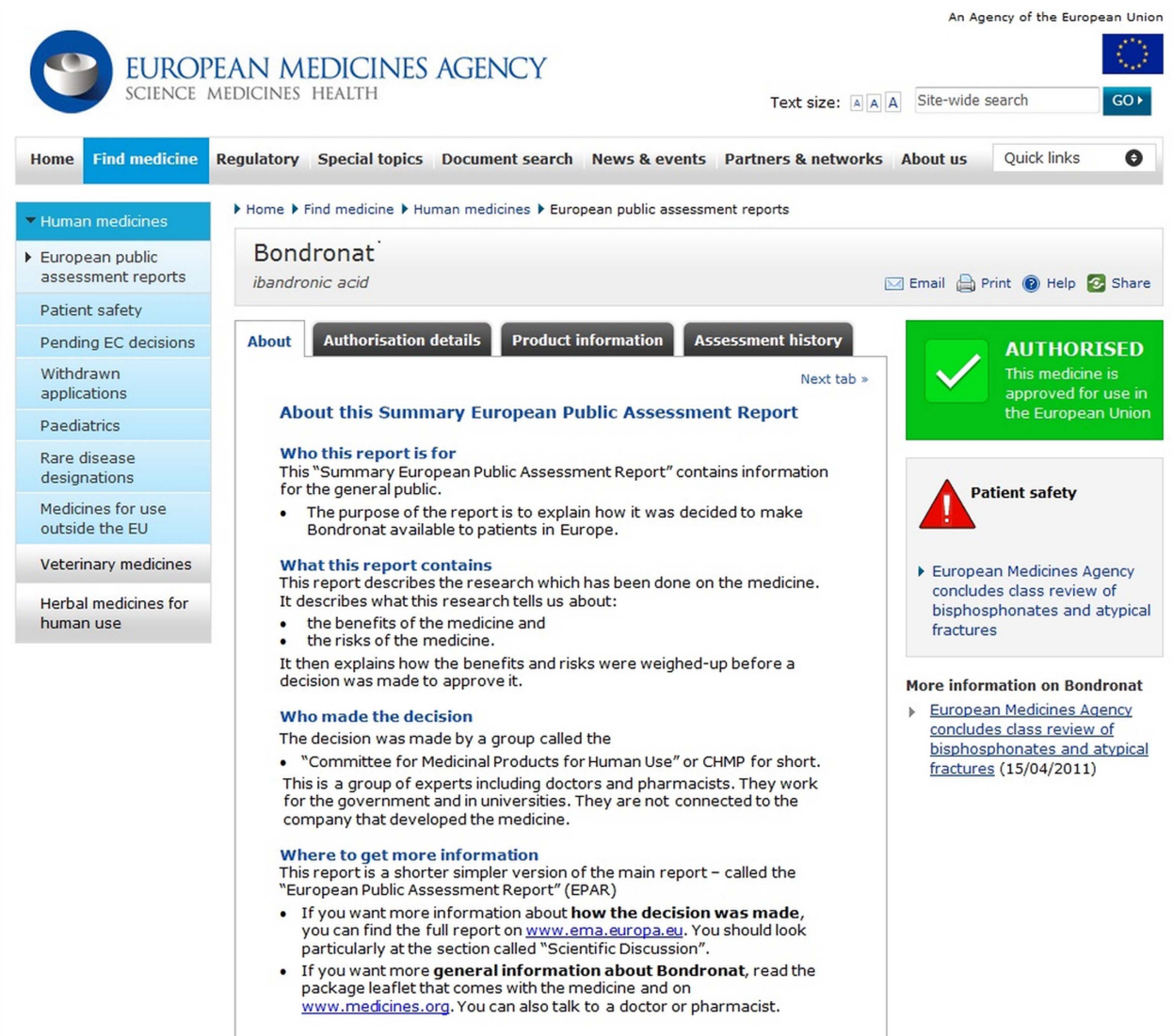

Figure 4 The revised EPAR summary on screen (round 4). 
E 2. How Bondronat is used

Bondronat should only be started by a doctor who has experience in treating cancer.

For high calcium levels

Bondronat is given as a drip

- This is either a 2 or 4 milli-gram $(\mathrm{mg})$ drip.

- The amount depends on how high the calcium levels are.

The drip will normally bring the blood calcium level down to normal levels within a week.

To prevent fractures

To prevent fractures, Bondronat is given as:

- 6 milli-gram $(\mathrm{mg})$ drip over at least 15 minutes - every three to four weeks or

- one tablet once a day in the early morning.

Special information about taking the tablets

1. The tablets have to be taken when the stomach is empty. This is because food may stop the medicine from getting into the body from the stomach. This means the best time is first thing in the morning.

- Before taking the tablet, the patient must not eat anything for at least six hours overnight

- After taking the tablet, the patient must wait at least 30 minutes before the first food or drink of the day.

2. The tablets can irritate your food pipe. The food pipe is the tube from the mouth to the stomach. This means the tablets must be from the

- whole - not chewed, sucked or crushed

- with a full glass of plain water (not sparkling water) - while standing or sitting up.

The patient must not lie down for one hour after taking the tablet.

Patients with kidney problems

Patients with moder ate or severe kidney problems should have Bondronat infusions at a lower dose over an hour. If taking the tablets, they take them every two days or every week.

3. How Bondronat was studied

Research studies into bone complications

There have been 3 main research studies of Bondronat in preventin

fractures in patients with breast cancer where the cancer has spread

to the bone:

- one study with the drip - in 466 patients

- two studies with the tablets - in a total of 846 patients.

What was Bondronat compared with?

In these studies, Bondronat was compared with "dummy" treatment.

This is where the drip or tablets contain no medicine (also called a

'placebo'). These studies each lasted 2 years:

What did the studies look for?

The studies looked for the number of new bone problems or complications. These included spine and other fractures. Also any

bone problems that needed radiother apy or surgery.

What did the studies show?

The results showed Bondronat was more effective than dummy

treatment in preventing bone problems.

Patients having Bondronat infusions or tablets did not get new

bone problems until 50-76 weeks. This compared with 33-48

weeks for patients on the dummy treatment.

Bondronat reduced the risk of having a fracture or other bone

problem by about $40 \%$ compared with placebo.

Research studies into high calcium levels

There have been 3 main studies in the treatment of high calcium levels caused by tumours. These lasted four weeks and involved 343 patients. What was Bondronat compared with?

Bondronat was not compared with any other treatments in these studies.

What did the studies look for?

The studies looked at any changes in blood calcium levels.

What did the studies show?

The results showed that Bondronat was effective in reducing high

calcium levels caused by tumours:

- A 2 milli-gram (mg) dose made the levels return to normal in about

half to two-thirds of patients

- A 4 milli-gram (mg) dose worked in about three-quarters of patients.

Figure 4 Continued.

I think it's good to know that somebody in authority has checked it out (P20)

Those who did not think it would be useful made comments about the complexity of the information. When asked whether people who were not patients would find it useful, the most common response was that carers or people who know someone with the indicated conditions might find it useful to read the
E 4. Possible side effects of Bondronat

Bondronat Drip

The most common side ef fect with a Bondronat drip is:

- High temperature or fever

This affects morethan 1 in 10 people.

Bondronat Tablets

The most common side effects with Bonodronat tablets are:

- feeling weak

- heartburn, feeling sick or stomach ache

- low blood calcium levels (hypo-calcaemia)

These affect less than 1 in 10 people.

Another common side effect with the tablet is to do with the food

pipe. This is the tube from the mouth to the stomach.

- The food pipe may be irritated or inflamed and an ulcer may

form.

- This can cause severe pain in the chest after swallowing food or

drink or feeling or being very sick.

This affects less than 1 in 10 people.

This is why the tablets must be taken

- with a full glass of water

- the patient must not lie down in the hour after taking the tablet.

It is also why the tablets must not be used in:

- people who have problems with their food pipe

- people who cannot stand or sit upright for at least an hour.

For the full list of side effects of Bondronat, see the Package Leaflet. Other risks

Bondronat should not be used in:

- people who may be hypersensitive (allergic) to ibandronic acid or people whe other ingredients.

- people with hypo-calcaemia

Bondronat should be used with care in patients who are sensitive to other bis-phosphonate medicines.

Bondronat should not be used in children.

E 5. Why Bondronat was approved

The experts on the Committee for Medicinal Products for Human Use (CHMP) have looked at the research studies for:

- the benefits of Bondronat

- the risks of Bondronat.

They have weighed up the benefits and risks. They have decided that the benefits are greater than its risks. This is why they have recommended that it be allowed to be made available on a

prescription.

The European Commission granted a marketing authorisation valid throughout the European Union for Bondronat on 25 June 1996. The marketing authorisation holder is Roche Registration Limited. The marketing authorisation is valid for an unlimited period.

This summary was last updated in 01-2010.

\begin{tabular}{|c|c|c|c|c|}
\hline Name & Language & & First published & Last updated \\
\hline $\begin{array}{l}\text { Dondronat : EPAR - } \\
\text { Summary for the } \\
\text { public }\end{array}$ & $\begin{array}{l}\mathrm{EN}=\text { English } \\
\mathrm{GO}\end{array}$ & $\checkmark$ & $09 / 06 / 2008$ & 08/03/2010 \\
\hline
\end{tabular}

This EPAR was last updated on 05/05/2011

- More detail is available in the Summary of Product Characteristics

Figure 4 Continued.

document. A few participants listed some groups of people who might utilise the information, for example, healthcare professionals $(n=4)$ and researchers $(n=2)$.

\section{DISCUSSION}

The principal finding of this research is that the current EPAR summary format could be improved, with only 6 of the 19 items of information found and understood (to the level required for package leaflets) for both the paper-based and screen formats. However, the revised format, guided by user testing with the target population, better met people's needs, where 14 and 16 points, respectively, met the target. 


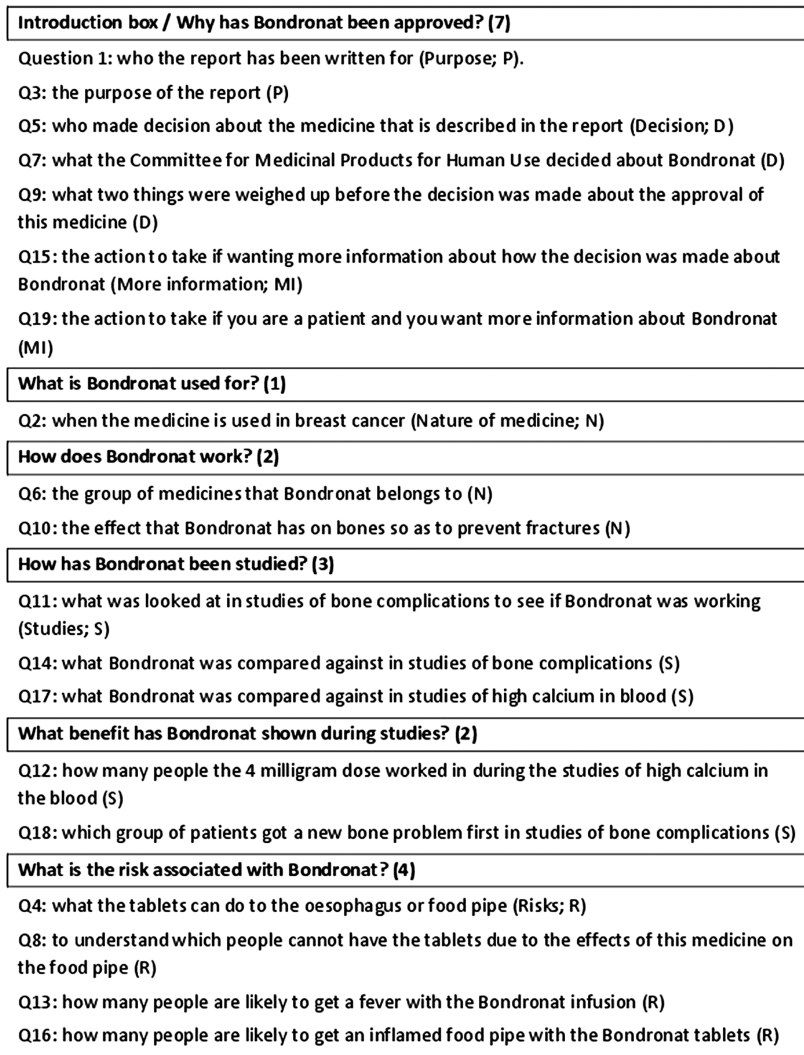

Figure 5 Key points of information tested.

As with most documents that are user tested, there were problems related to both finding information and understanding the information. Importantly, the heading

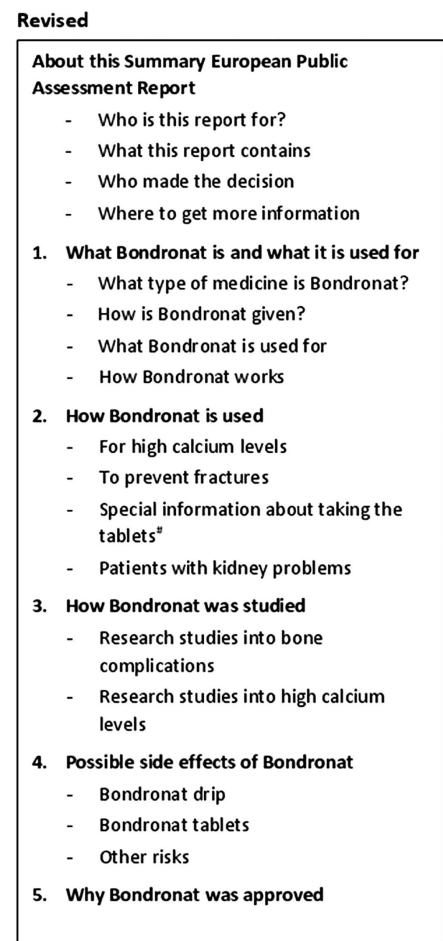

Figure 6 Original and revised heading and subheading structure. structure did not work well, and points of information need to be placed where lay people would expect to find them (rather than where professionals are used to placing them). The addition of new numbered headings and subheadings (along with the inclusion of an 'In this leaflet' listing near the beginning) led to improvements in performance. Important points relating to the content were the need to clarify the purpose of the document at the beginning: saying what it is, and who it is for. The key recommendations are described in box 1 .

A previous study of EPAR Summaries in Denmark by Askehave and Zethsen ${ }^{4}$ focused on their nature as a 'mandatory genre'. The study involved a questionnaire on lay respondents' opinion of the text, alongside an exercise in which participants marked problem words, sentences or paragraphs in the document. The authors concluded that most participants did not think the summaries fulfil their purpose of providing information which is understandable and useful to lay persons. Our findings with a UK population concur with those in Denmark, and the addition of a performance-based testing method also pointed the way to improvements.

\section{LIMITATIONS}

The study was based on one EPAR summary, which was of a representative size for such summaries. However, an EPAR summary for a medicine for cancer may be substantially different from one on a medicine for epilepsy or schizophrenia in terms of what the public need to know. This work would be enhanced by similar studies

\section{Box 1 Recommendations}

\section{General information design}

- Appropriate use of bullets, no italics or boxes.

- Two columns for paper version.

- Clear signposting with main headings (numbered) and subheadings which work for lay people (see headings structure in figure 2).

- Still a need for both hard copy and on-screen versions. The printable version from the website needs to be designed to work well on paper-not just replicate what is on the screen.

Key messages

- Clarify the purpose of the document up front: what it is and who it is for.

- Keep the information about each study (or set of studies) together, that is, do not separate out 'How has been studied' and 'What benefit has been shown in studies'.

- The general public may not be the right audience? It may be more usefully aimed at people who are take or are considering taking the medicine concerned and people from relevant patient groups, rather than the general public.

\section{Future developments}

- Clarify relationship with Package Leaflet-presenting both together would allow removal of most of the duplicated information, and allow the European Public Assessment Report summary to focus on the studies, their findings and the decision-making process. 
on different types of medicine. However, in the meantime, most of the improvements identified were generic, and not specific to the type of medicine, and would be applicable to most summaries.

We refer later in this section to studies which show that patients want more balanced information, including benefit information. However, we did not include such a heading in the final version of the EPAR summary, for example, 'What are the benefits of Bondronat?' The inclusion of such a heading may need to be studied in future research on these documents.

\section{Relationship with wider literature}

Previous studies examining health literacy have also found that many people have difficulty in understanding health information in the $\mathrm{UK},{ }^{13}$ Australia $^{14}$ and the $\mathrm{USA}^{15}$ including statutory medicines information. ${ }^{16}$ Furthermore, a review of drug information for consumers and patients with a focus on the EU concluded that 'drug authorities' should see themselves more as a source of medicine information for patients. ${ }^{17}$ This study has also demonstrated the concept that unnecessary complexity can act as a barrier to patient understanding ${ }^{2}$ - shown here in the fact that a minority of the items of information could be found and understood. What this work does not show is whether the revised summaries enable a wider ability to become more empowered to engage with the healthcare process-part of the wider nature of health literacy ${ }^{18}$ - this needs further study.

\section{What is the target group?}

Most stakeholders would agree that people should be able to find out how the decision to license a medicine was made. However, the full EPAR is never going to be a document which is going to be useful to lay people, and EPAR summaries are a laudable attempt to open up the medicines licensing process in the EU. Although the intention was that they should be understandable to the public, their effectiveness has not been previously tested. Owing to the target group, as stated by the EMA, being 'the public', the participants in this series of tests were representative of the general population, weighted to more older people and including people of lower educational attainment. However, one finding of the study is that it was not certain for some participants as to whether this type of information would be useful to them personally. Although not stated by participants, it could be argued that the target group should be people with the condition for which the medicine is used, who are actively involved in their healthcare, and people from relevant patient groups (rather than members of the public generally). If so, then future testing should be undertaken with people from these target groups.

\section{Relationship with package leaflet}

Some participants raised the question of the relationship between the EPAR summary and the Package Leaflet. It is clear that there is considerable overlap between the two documents. The EPAR summary has general information, also contained in the leaflet (about what the drug is, what it is used for and how it is used, along with some side effects). The rest of the document, detailing the studies and the decision process would not make sense without that background information. However, the background information does appear to be problematic, and takes the focus away from the key points relating to the research studies and the decision process. One option would be to incorporate the patient leaflet (or parts of it) into an EPAR summary 'package'. This could comprise an introduction, which describes the purpose of the 'package', and explain that the reader should first read the leaflet, and then the EPAR summary. The latter could then focus only on the studies and the decision-making process, that is, the information under the current headings 'How Bondronat was studied' and 'Why Bondronat was approved'.

A notable difference between the EPAR summary and the package leaflet is that the former explicitly mentions the likelihood of benefit. This is generally not present in patient leaflets, certainly not with any numerical information about the benefit. However, there is increasing support to include more benefit information in package leaflets, ${ }^{19}$ to answer the call from patients that they want more balanced information on which they can make decisions about whether a medicine is right for them. ${ }^{20}$ At present, including this information is a problem, because of the current requirement that the leaflet is based on the SmPC. A second problem is that the information needs to be presented in a way that is understandable to the public. It could be argued that including benefit information based on the EPAR summary (in the revised format developed in this study) would solve both problems.

This study is further evidence to support the applicability and usability of the user-testing method to improve a variety of health-related information. It also shows that paper-based EPAR summaries as well as on-screen versions continue to be needed by different groups of the population. Importantly, the information needs to be appropriately formatted for each mediumas used in this study.

Finally, this study has shown that there is support for the idea of a document which describes in patient friendly terms, the studies on which the decision was made to make the medicine available in the EU. However, the EPAR summary document did not perform well in user testing, but the testing highlighted the problems, and application of good practice resulted in revised formats which performed well.

Acknowledgements The authors would like to thank the participants who took part in the tests, and also Isabelle Moulon, Juan Garcia and staff at the European Medicines Agency for their encouragement and support. They would also like to thank Susannah Barnes and Kirstin Blackwell who helped devise the questionnaire, manage the testing and assisted with the analysis, Wayne Middleton for preparing the revised version of the on-screen summary and David Alldred for advice on the discussion. 
Contributors DKR conceived the study, and worked on the study design with DB; DKR led data interpretation, with support from DB. DKR wrote the article and both authors contributed to the final draft.

Funding This research was funded internally by the University of Leeds.

Competing interests DKR is the Co-founder and Academic Advisor to Luto Research which undertook the testing and which develops, refines and tests health information materials. DB is the General Manager at Luto Research.

Ethics approval The study was granted research ethics approval by the University of Leeds School of Healthcare Research Ethics Committee. Each participant was paid £20 for travelling and other expenses.

Provenance and peer review Not commissioned; externally peer reviewed.

Data sharing statement No additional data are available.

Open Access This is an Open Access article distributed in accordance with the Creative Commons Attribution Non Commercial (CC BY-NC 3.0) license, which permits others to distribute, remix, adapt, build upon this work noncommercially, and license their derivative works on different terms, provided the original work is properly cited and the use is non-commercial. See: http:// creativecommons.org/licenses/by-nc/3.0/

\section{REFERENCES}

1. European Medicines Agency. European Public Assessment Reports. http://www.ema.europa.eu/ema/index.jsp?curl=pages/ medicines/general/general content 000433.jsp (accessed 12 Apr 2013).

2. Medicines and Healthcare Products Regulatory Agency (MHRA). Always read the leaflet: getting the best information with every medicine. Report of the Committee on Safety of Medicines Working Group on Patient Information. London: The Stationery Office, 2005.

3. Raynor DK. User testing in developing patient medication information in Europe. Res Soc Admin Pharm 2013. http://dx.doi.org/ 10.1016/j.sapharm.2013.02.007

4. Askehave I, Zethsen KK. Mandatory genres: the case of European Public Assessment summaries. Text Talk 2008;28:167-91.

5. Raynor DK, Knapp P, Silcock J, et al. User-testingas a method for testing the fitness-for-purpose of written medicine information. Patient Educ Couns 2011;83:404-10.
6. Knapp P, Raynor DK, Silcock J, et al. Can user testing of a clinical trial patient information sheet make it fit-for-purpose?-a randomized controlled trial. BMC Med 2011;9:89.

7. BNF paper,Harris E, Enright D. New words for cautionary and advisory labels make them easily understood. Pharm J 2011;286:278-9.

8. Raynor DK. Health literacy. Is it time to shift our focus from patient to provider? BMJ 2012;344:e2188.

9. Raynor DK, Blenkinsopp A, Knapp $\mathrm{P}$, et al. A systematic review of quantitative and qualitative research on the role and effectiveness of written information available to patients about individual medicines. Health Technol Assess 2007;11:iii-160.

10. Raynor DK, Dickinson D. Key principles to guide development of consumer medicines information. Ann Pharmacother 2009;43:700-6.

11. European Commission. Guideline on the readability of the labelling and package leaflet of medicinal products for human use. http://ec. europa.eu/health/files/eudralex/vol-2/c/2009_01_12_readability_ guideline final en.pdf (accessed 12 Apr 2013).

12. Medicines and Healthcare Products Regulatory Agency (MHRA). Guidance on the user testing of patient information leaflets. http:// www.mhra.gov.uk/home/groups/pl-a/documents/publication/ con1004417.pdf (accessed 21 Apr 2013).

13. Bostock S, Steptoe A. Association between low functional health literacy and mortality in older adults: Iongitudinal cohort study. BMJ 2012;344:e1602.

14. Australian Bureau of Statistics. Australian social trends 2009: health literacy. http://www.abs.gov.au/AUSSTATS/abs@.nsf/Lookup/4102. OMain+Features20June+2009

15. Nielsen-Bohlman L, Panzer AM, Kindig DA. eds. Health literacy: a prescription to end confusion. National Academies Press, 2004

16. European Commission Enterprise and Industry Directorate General. High Level Group on innovation and provision of medicines. Recommendations for action; 2002. http://ec.europa.eu/enterprise/ sectors/healthcare/competitiveness/pharmaceutical-forum/g10en.htm (accessed 20 Jun 2013).

17. Narhi U. Drug information for consumers and patients-a review of the research. Finland: National Agency for Medicines, 2006.

18. Nutbeam D. The evolving concept of health literacy. Soc Sci Med 2008;67:2072-8.

19. European Medicines Agency. Human Product Information Annotated Template v 9.0. http://www.emea.europa.eu/docs/en_GB/document_ library/Template or form/2009/10/WC500004368.pdf (accessed 12 April 2013)

20. Hamrosi K, Dickinson R, Knapp P, et al. Its for your benefit: exploring patients' opinions about the inclusion of textual and numerical benefits information in medicine leaflets. Int $J$ Pharm Prac 2013;21:207-15. 